\title{
MR SIALOGRAPHY AND CONVENTIONAL SIALOGRAPHY IN SALIVARY GLAND AND DUCT PATHOLOGIES: A COMPARATIVE STUDY
}

Amarnath Chellathurai ${ }^{1}$, Sathyan Gnanasigamani², Shivashankar Kumaresan 3 , Suhasini Balasubramaniam ${ }^{4}$, Kanimozhi Damodarasamy5, Komalavalli Subbiah', Sivakumar Kannappan7, Balaji Selvaraj8

1 Professor and HOD, Department of Radiodiagnosis, Stanley Medical College, Chennai. ${ }^{2}$ Associate Professor, Department of Radiodiagnosis, Stanley Medical College, Chennai. ${ }^{3}$ Assistant Professor, Department of Radiodiagnosis, Stanley Medical College, Chennai. ${ }^{4}$ Associate Professor, Department of Radiodiagnosis, Stanley Medical College, Chennai. 5 Junior Resident, Department of Radiodiagnosis, Stanley Medical College, Chennai. ${ }_{6}^{6}$ Assistant Professor, Department of Radiodiagnosis, Stanley Medical College, Chennai. ${ }^{7}$ Assistant Professor, Department of Radiodiagnosis, Stanley Medical College, Chennai. ${ }^{8}$ Assistant Professor, Department of Radiodiagnosis, Stanley Medical College, Chennai.

ABSTRACT

\section{BACKGROUND}

MR Sialography has become an alternative method for imaging the salivary gland and duct. MRI is a non-invasive technique with advantages of superior tissue discrimination and multiplanar facility. MRI has no radiation hazard as compared to the conventional sialography and CT sialography; 3D CISS sequence gives details of salivary gland ducts and sialoliths.

\section{AIM}

To compare the accuracy of the conventional sialography and MR Sialography in the diagnosis of salivary gland and duct pathologies.

\section{MATERIALS AND METHODS}

A prospective study was conducted in 54 patients with clinical diagnosis of non-tumorous salivary gland pathologies; 65 salivary glands of the above patients were subjected to conventional sialography and MR Sialography. The diagnostic accuracy of conventional sialogram and MR Sialogram was studied by correlating with surgical, histopathological findings and clinical followup. Three patients were excluded from the study, as there was inability to cannulate during conventional sialography. Conventional sialogram was performed using an $800 \mathrm{~mA}$ fluoroscopy machine. MRI was performed using a 1.5 Tesla unit. Dedicated MRI of the salivary glands was performed comprising of T1, T2, FS, 3D CISS, DWI sequences.

\section{STATISTICAL ANALYSIS}

The MR and conventional sialographic findings were compared with the final diagnoses. All data were calculated for the number of investigated salivary glands. Sensitivity, specificity, positive and negative predictive values were calculated for the detection of pathologies which include acute sialadenitis (MRI during the episode and conventional sialogram after the episode), chronic sialadenitis and sialolithiasis.

\section{RESULTS AND CONCLUSION}

There was good correlation between MRI features and surgical, histopathological findings/clinical followup. MRI showed an overall accuracy in par with conventional sialography. Hence, MRI is extremely useful in the diagnosis of salivary gland and duct pathologies.

\section{KEYWORDS}

MR Sialography, Conventional Sialography, Parotitis, Sialectasis, Sialolithiasis.

HOW TO CITE THIS ARTICLE: Chellathurai A, Gnanasigamani S, Kumaresan S, et al. MR sialography and conventional sialography in salivary gland and duct pathologies: a comparative study. J. Evolution Med. Dent. Sci. 2016;5(52):3367-3372, DOI: $10.14260 /$ jemds/2016/778

\section{INTRODUCTION}

The salivary glands are tubuloacinar exocrine glands, whose ducts open into oral cavity.

Financial or Other, Competing Interest: None.

Submission 18-03-2016, Peer Review 20-04-2016,

Acceptance 26-04-2016, Published 28-06-2016.

Corresponding Author:

Amarnath Chellathurai,

Professor and HOD,

Department of Radiodiagnosis,

\#301, Stanley Medical College,

Chennai-600001, India.

E-mail: amarrd02@yahoo.co.in

DOI: $10.14260 /$ jemds $/ 2016 / 778$
Three pairs of major salivary glands are parotid, submandibular, and sublingual glands. Minor salivary glands are scattered throughout oral mucosa and submucosa, palate, paranasal sinuses and trachea.

The salivary glands can be imaged by X-ray, ultrasound, CT, MRI and radionuclide studies. The ductal system can be imaged by means of Sialography. CT and X-ray Sialography are done following injection of iodinated contrast media into the ductal system. MR Sialography is done using heavily T2 weighted acquisition techniques without administration of contrast media.(1,2) Hence, it is non-invasive and radiation free.(2) Multiplanar imaging can be done using MRI.

It can also evaluate bilateral parotid and submandibular glands and their ducts. Extraluminal structures can be well 
studied using MRI. Conventional sialography depicts the main salivary duct and intraglandular ducts up to tertiary branches. MR Sialography depicts the main duct, primary and secondary branching ducts, but could not demonstrate tertiary branches.(1,3,4) In this study, we compare the accuracy of the conventional sialography and MR Sialography in the diagnosis of salivary gland and duct pathologies.

\section{MATERIALS AND METHODS}

Ethical Committee clearance was obtained. Written informed consent was obtained from all patients. The patients with salivary gland symptoms were included in the study. Patients with clinical suspicion of salivary gland tumours, past salivary gland surgeries, pacemaker, claustrophobia, pregnancy were excluded from the study.

It is a prospective study conducted in 54 patients who were referred with clinical diagnosis of acute sialadenitis, chronic sialadenitis and sialolithiasis; 65 salivary glands of the above patients were subjected to conventional sialography and MR Sialography. MR Sialography was done in all patients at first visit. Conventional sialography was done on the same day in all patients except cases of acute sialadenitis, for whom it was deferred and done after resolution of symptoms.

The acute sialadenitis patients were followed up with their treatment. Rest of the patients were followed up with histopathological reports and surgical specimens. Three patients were excluded from the study, as there was inability to cannulate the duct in conventional sialography even after repeated attempts.

\section{Conventional Sialography}

Conventional sialography was performed by using Allengers $800 \mathrm{~mA}$ fluoroscopic equipment. Plain radiographs were obtained in standard antero-posterior and lateraloblique projections to detect radiopaque sialoliths. $(1,5,6)$

Secretagogue-like fresh lemon was used before the commencement of the study, so that the intraoral opening of the parotid and submandibular ducts could be visualised well. After identifying the opening, lacrimal dilators are used to dilate it to facilitate cannulation.(1) Sialographic cannulas which are connected to polyethylene tube are inserted into the duct and connected to a 5-mL syringe. Non-ionic iodinated contrast media iohexol is used; $1-1.5 \mathrm{~mL}$ of contrast for parotid and $0.2-0.5 \mathrm{~mL}$ for submandibular gland are injected slowly by using manual pressure. The injection is performed under fluoroscopic control to achieve optimum ductal filling. Spot radiographs were obtained in anteroposterior and lateral-oblique projections to document the examination. Post evacuation radiography was obtained in all patients by repeating the administration of lemon. $(1,5,4)$

\section{MRI with MR Sialography}

MR imaging was performed on a 1.5T scanner (Siemens, Magnetom, Aera) using head coil. Prior to MR imaging, the patients were given lemon juice to stimulate salivation.

Axial fast spin-echo T2 weighted fat suppressed sequence $(2.0 \mathrm{~min})$ and axial fast spin-echo T1 weighted sequence $(2.01 \mathrm{~min})$ were obtained in all patients. For MR Sialography, three-dimensional CISS sequence was performed. Contralateral glands and ducts were also evaluated and served as a control. The 3D CISS sequence with field of view 250, slice thickness $1 \mathrm{~mm}$, TR-2350 ms, TE-569 ms, matrix size - $448 \times 448$, scan time - 4 min 20 secs was acquired in the axial plane. Total scan time was $8 \mathrm{~min} 21 \mathrm{secs}$. The acquired 3D CISS data were reformatted with a Maximum Intensity Projection (MIP) and Multiplanar Reconstruction (MPR) in order to generate axial images and oblique sagittal images parallel to the submandibular/parotid duct. Diffusion weighted imaging was done in cases suspected to have abscess.

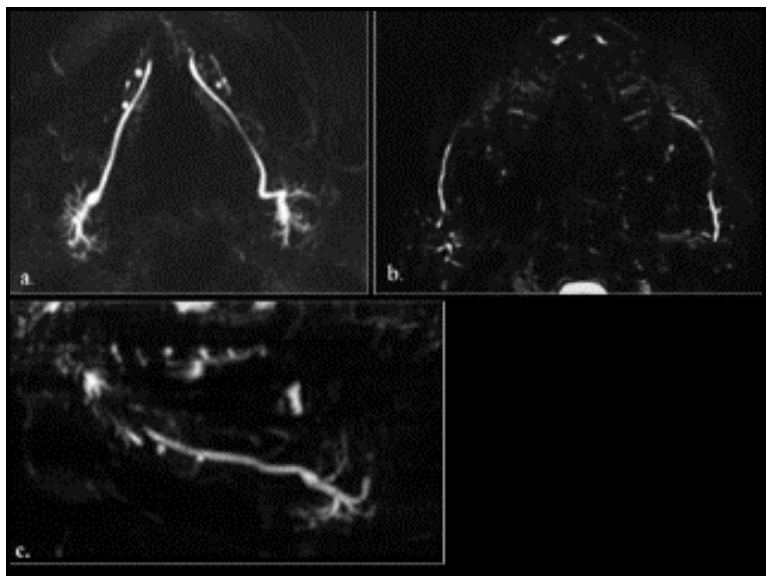

Fig. 1: 3D-CISS in a Healthy Volunteer showing Normal Appearance of a. Bilateral Submandibular Gland Duct, $b$ Bilateral Parotid Gland Duct, c. Entire Course of the Left Submandibular Duct in Sagittal Reformation

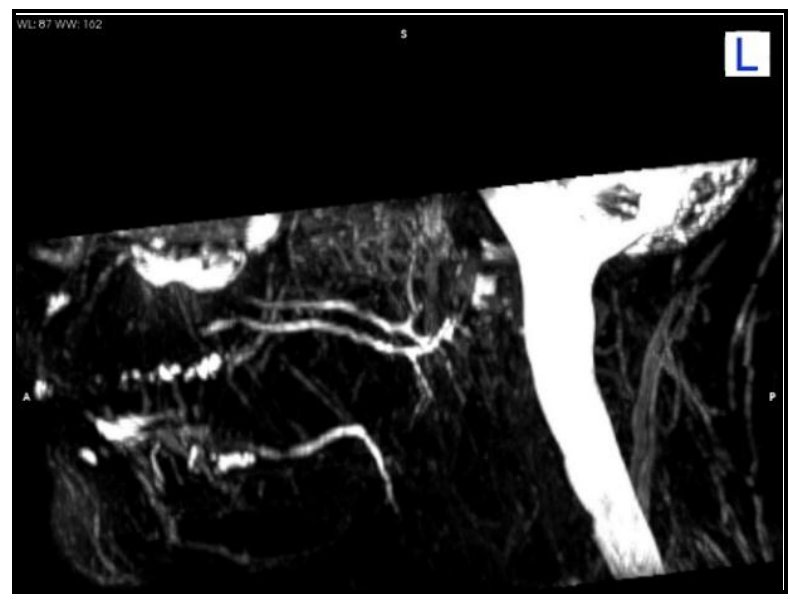

Fig 2: 3D MIP (Maximum Intensity Projection) showing Bilateral Parotid and Submandibular Ducts in a Single Image

\section{Image Interpretation}

The conventional and MR Sialographic images were read by two experienced investigators independently.

Acute sialadenitis was diagnosed when there was altered signal intensity in the gland with local pain and swelling in the region. Chronic sialadenitis was diagnosed when there was change in the calibre of the duct, sialectasis. Sialoliths were identified when there was filling defect or void in the course of the duct. Images were interpreted as normal if there were no ductal dilatation, cystic lesions, sialoliths, cystic structures and tumour.

\section{DISCUSSION}

Sialolithiasis

In cases of salivary obstruction, the most common complaint was local pain and swelling. Systemic symptoms were 
present in a few patients. Sialolithiasis is most commonly noted in the submandibular glands. $(7,4)$ X-ray, USG and CT enable the identification of calculus. Ultrasound is however inferior to CT in differentiating a solitary large ductal calculus from a cluster of small calculi. The effect of the calculi and patency of the ductal system can be identified by conventional sialography, DSS or MR Sialography. MRI sialography is useful to look for strictures following passage of calculus. $(8,9)$

Conventional sialography, DSS are invasive techniques and cannot be performed in the acute setting due to the possibility of exacerbating the symptoms associated with the existing infection. The act of instrumentation of the already inflamed gland will irritate and may cause post-traumatic oedema or stricture, which will aggravate the infection. The inflammatory products enter the periphery of the gland due to the retrograde injection of the contrast. This may also cause displacement of the calculus. $(10,8)$

MR Sialography is a non-invasive technique. It can demonstrate ductal patency comparable to other techniques. MR Sialogram has the advantage of demonstrating the part of the duct on either side of the stricture or obstruction. MRI can identify the areas of stricture, where the stone had already resided.

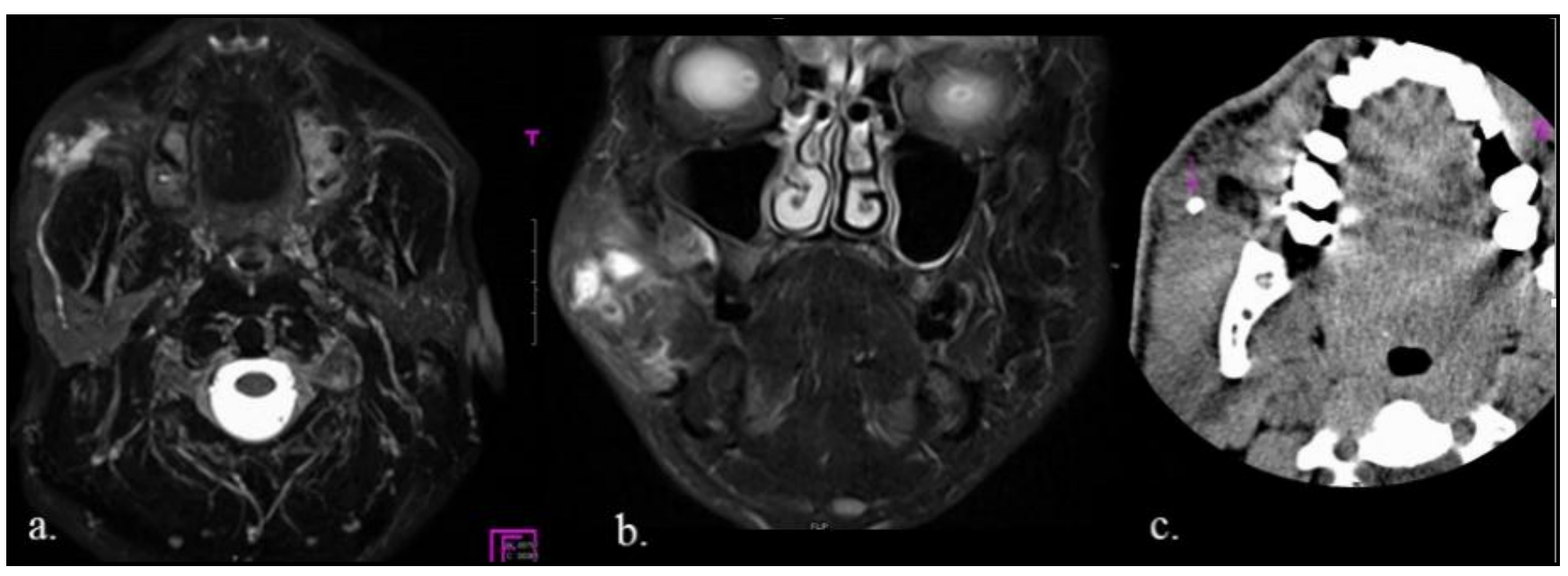

Fig. 3: a. MR Sialogram MIP Image, b. T2 FS Coronal Image, c. Axial CT Neck of a 29 yrs. Male Patient showing Calculus in the Right Parotid Duct causing Obstruction of the Duct

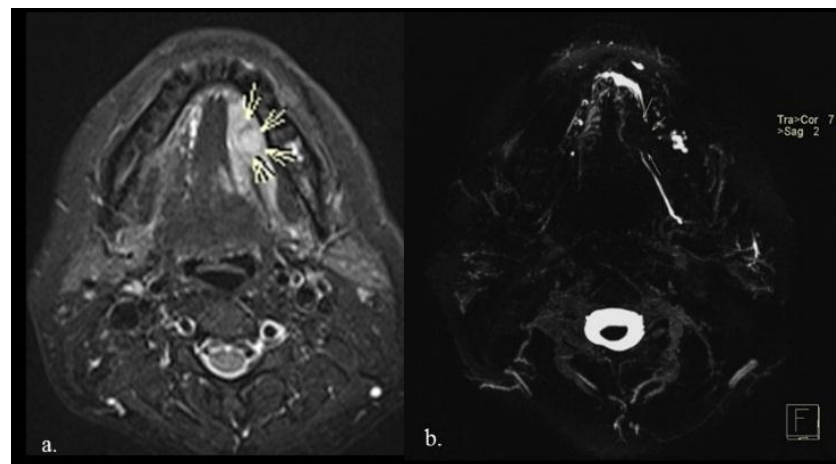

Fig. 4: a. MR Sialogram MIP Image, b. Axial T2 FS Neck of a 39 yrs. Male Patient showing Calculus in the Left Submandibular Duct causing Obstruction of the Duct with Adjacent Inflammation

Occasionally, an abscess in the gland that is associated with infiltration of the subcutaneous tissue might be present. In such cases, the presence of sialolith as the cause for the abscess should be excluded on a non-enhanced CT scan, US scan or conventional radiograph.

Contrast-enhanced CT and MR imaging are currently the best ways to demonstrate a glandular abscess. Because of the fatty attenuation and intensity that is intrinsic to the parotid glands, particularly as one ages abscesses are particularly well seen on enhanced CT scans and postcontrast fat-saturated T1-weighted MR images. Diffusion weight imaging has been useful in detection of the abscess. The differential diagnosis for abscess include superinfected HIV related cysts, suppurative parotid lymph nodes and cystic degeneration of neoplasms with or without superimposed infection. $(6,10,8,9)$

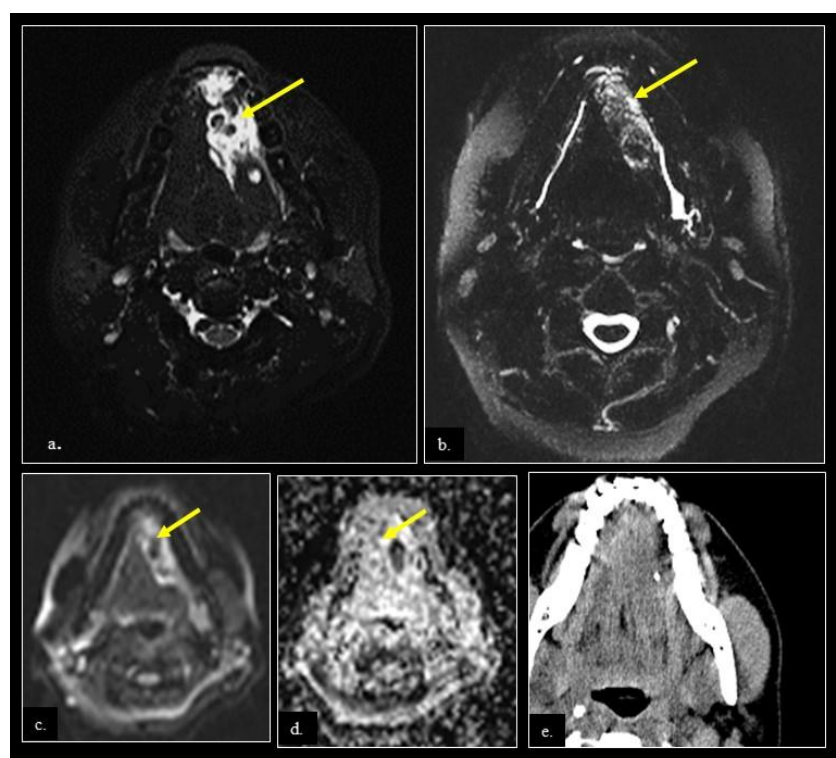

Fig. 5: a. Axial T2 FS b. MR Sialogram MIP Image, c. DWI d. $A D C$ Images at the Floor of Mouth showing Calculus in the Left Submandibular Duct causing Obstruction of the Duct with Adjacent Abscess (Arrow). E. Axial CT Image of the same Patient showing Calculus

Sialadenitis

The most common cause of acute sialadenitis is infection. This is most commonly due to pathogens ascending from the oral cavity due to decreased salivary flow in conditions like 
prior infections, dehydration, surgery, irradiation and obstructing lesions such as stones or tumours.

Imaging is useful in detecting and defining the location of non-palpable and multiple calculi. Occasionally, a mucus plug instead of the calculus may be a cause of ductal obstruction and consequent acute sialadenitis.

US shows diffusely enlarged gland with hypoechogenicity, heteroechoic pattern and increased vascularity in acute stages. Abscess formation may or may not be present. In chronic stages, the gland may be normal or small in size with decreased echogenicity and vascularity and heteroechoic pattern.(7,6) On CT and MR imaging, sialadenitis appears as moderate-to-intensely enhancing, diffusely enlarged salivary gland with or without abscess formation. Intraparenchymal and regional lymphadenopathy may be present. There is associated soft tissue stranding of adjacent fat and cervical fascia. As MRI is more sensitive to oedema, it picks up early sialadenitis and even inflammation of salivary ductal walls (Sialodochitis). (7,4,9) MRI can evaluate both glands simultaneously and MRI in coronal plane is very helpful in delineating the relationship of salivary gland lesions with other structures in the floor of mouth as in ranula (A mucous retention cyst) and in demonstrating the invasion of skull base, especially in parotid malignancy. $(3,8,9)$

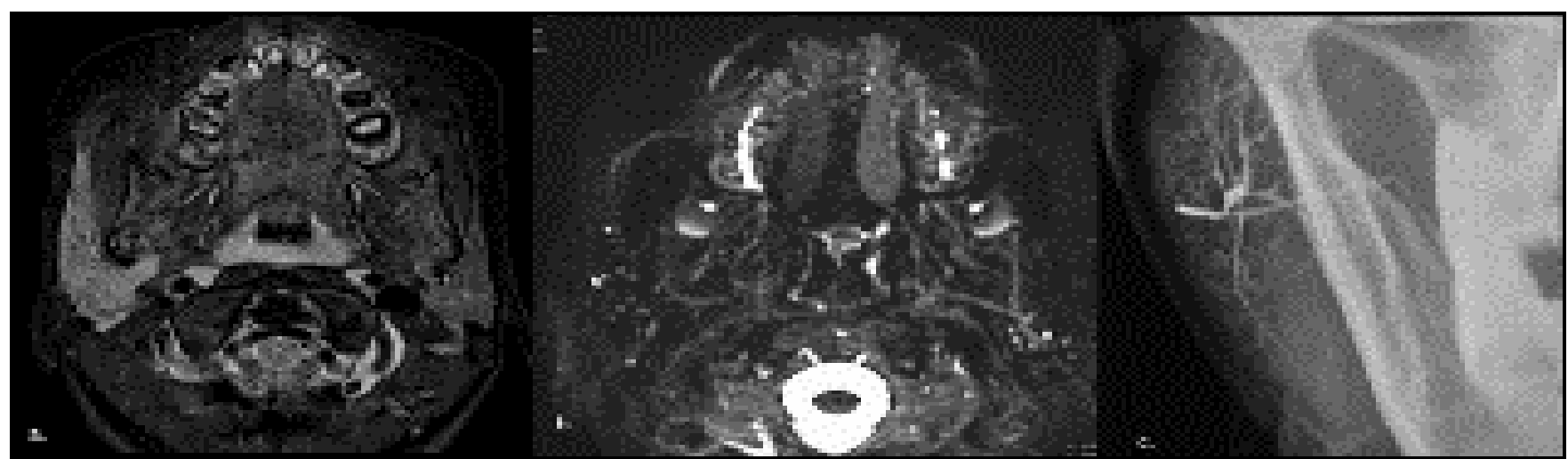

Fig. 6: a \& b MR of a 47 yrs. Female- a. Axial T2FS showing Hyperintensity in the Right Parotid Gland b. MR Sialogram MIP Image-Normal, c. Conventional Sialography Performed after the Treatment

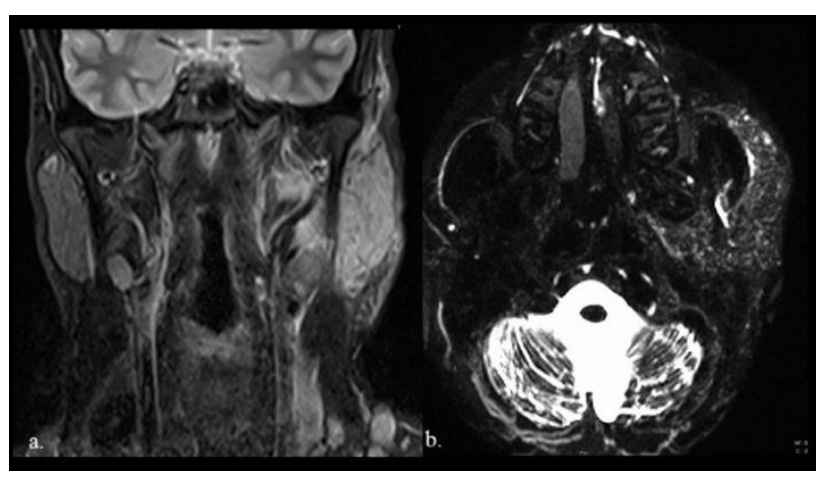

Fig. 7: a \& b MR of a 21 yrs. Female- a. Coronal T2FS showing Hyperintensity in the Left Parotid Gland $b$. MR Sialogram MIP Image-Normal
The causes for chronic sialadenitis include recurrent infection (Mycobacterial infections, syphilis, cat-scratch fever, toxoplasmosis, actinomycosis), prior irradiation, autoimmune disease, sarcoidosis and idiopathic. $(4,10)$ On MR Sialography, it reveals pruning or truncation of major ducts and globular peripheral collections, as periphery of the gland is the usual site of initiation of this pathologic process. Presence of microabscesses may mimic peripheral collections of the autoimmune process. In these cases of painful salivary gland associated with chronic sialadenitis, in the absence of calculi, MR Sialogram gives a clue about the ductal system. Strictures lead to stasis of the secretions and aggravate the infection. $(7,4)$

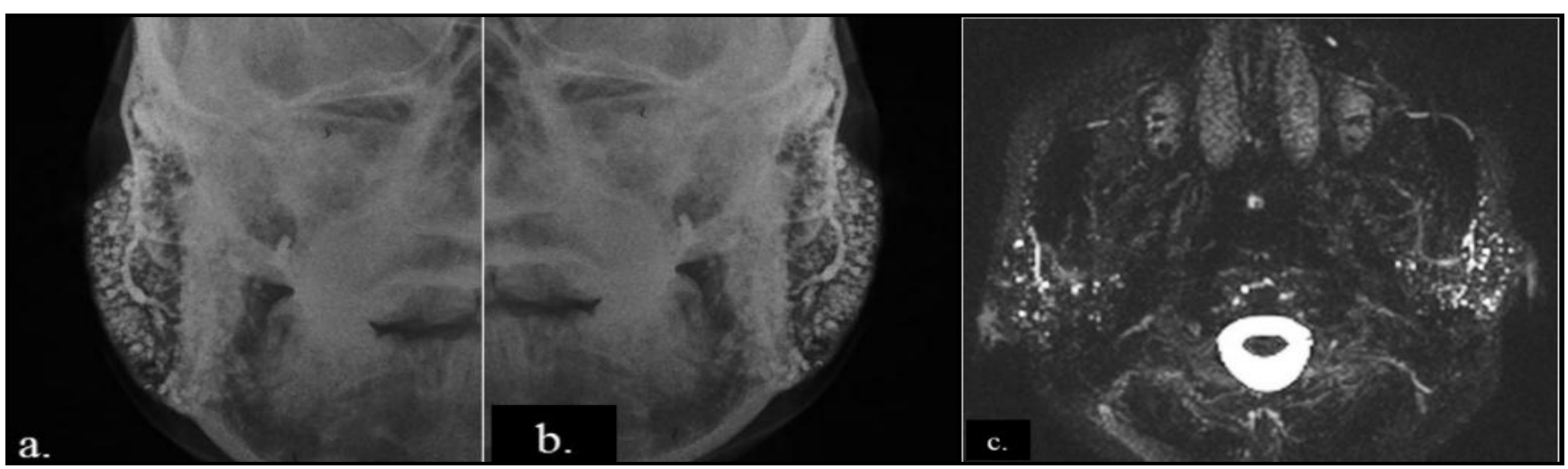

Fig. 8: a, b: Conventional Sialography, c. 3D CISS MIP Image in a 22 Years Female Patient showing Multiple Tiny Globular Collections (Of Contrast Material in Conventional Sialography) in the Bilateral Parotid Gland. Patient was Diagnosed to have Sjogren's Syndrome 


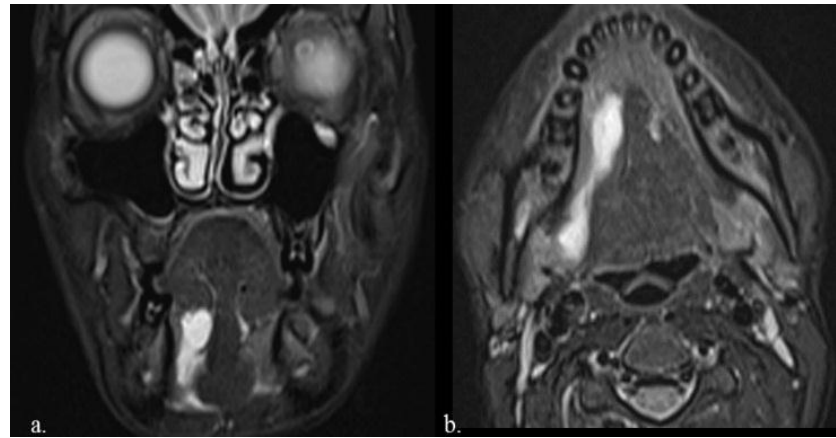

Fig. 9: $a$ \& b-MR of a 16 yrs. Female - a. Coronal b. Axial T2FS showing Sialectasis of the Right Submandibular Gland

\section{STATISTICAL ANALYSIS}

The MR and conventional sialographic findings were compared with the final diagnoses. All data were calculated for the number of investigated salivary glands. Sensitivity, specificity, positive and negative predictive values were calculated for the detection of the acute sialadenitis (MRI during the episode and conventional sialogram after the episode), chronic sialadenitis and sialolithiasis.

Chronic sialadenitis was the most frequent diagnosis, found in twenty six salivary glands (Sixteen parotid glands and ten submandibular glands). Patients referred with clinical diagnosis of acute sialadenitis, underwent MRI with MR Sialography during the acute phase, which showed altered signals in gland with normal ductal system. Conventional sialography was done after a course of antibiotic in nineteen glands (Twelve parotid glands and seven submandibular glands), which also showed normal ductal system. Sialolithiasis was diagnosed in fifteen glands (Six parotid and nine submandibular). MRI was false negative in two patients. MRI has an additional advantage of demonstrating adjacent soft tissue pathology. Five of patients with sialolithiasis showed abscess formation (With help of diffusion weighted imaging) due to obstruction. In two other investigated glands, parenchymal cystic lesion ( $n=1$ ) (Fig. 10) and intraparotid lymphadenitis $(n=1)$ were the diagnosis (Table 1).

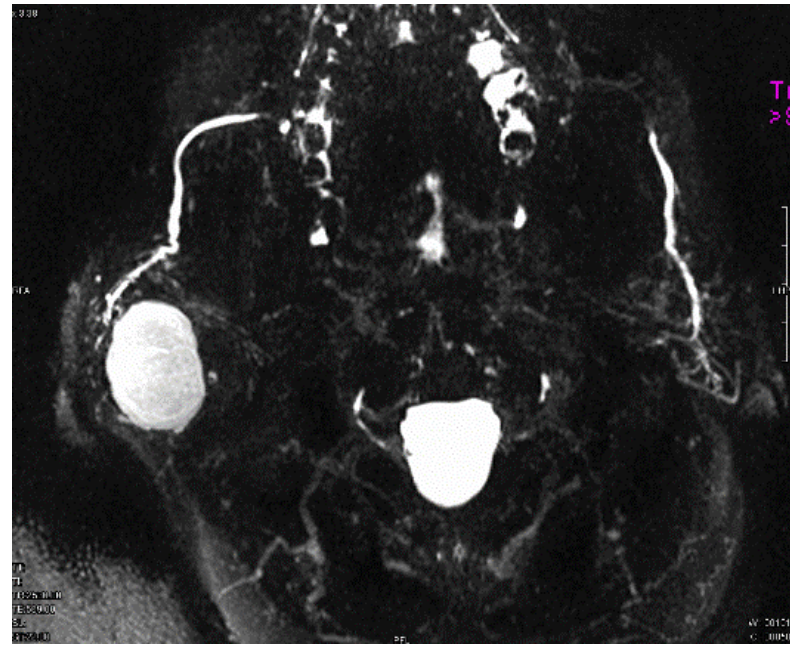

Fig. 10: 64 yr. Male Patient with Right Parotid Swelling and Pain, had Cystic Lesion in the Superficial Lobe of the Parotid with Normal Ductal Structures. Diagnosis of Cystic Warthin's Tumour was made on HPE

\begin{tabular}{|c|c|c|c|}
\hline Diagnosis & $\begin{array}{c}\text { No. of } \\
\text { Salivary } \\
\text { Glands } \\
\end{array}$ & Parotid & $\begin{array}{c}\text { Submandibular } \\
\text { Gland }\end{array}$ \\
\hline $\begin{array}{c}\text { Chronic } \\
\text { sialadenitis }\end{array}$ & 26 & 16 & 10 \\
\hline $\begin{array}{c}\text { Acute } \\
\text { sialadenitis }\end{array}$ & 19 & 12 & 7 \\
\hline Sialolithiasis & 15 & 6 & 9 \\
\hline Others & 2 & 2 & 0 \\
\hline
\end{tabular}

Acute sialadenitis, chronic sialadenitis and sialolithiasis were the three frequent diagnoses sensitivity, specificity and positive and negative predictive values for MR Sialography and conventional sialography were tabulated in Table 2 .

\begin{tabular}{|c|c|c|c|c|c|c|}
\hline \multirow{2}{*}{$\begin{array}{c}\text { Performance } \\
\text { Measure }\end{array}$} & \multicolumn{2}{|c|}{ Acute Sialadenitis } & \multicolumn{2}{c|}{ Chronic Sialadenitis } & \multicolumn{2}{c|}{ Sialolithiasis } \\
\cline { 2 - 7 } & $\begin{array}{c}\text { MR } \\
\text { Sialogram }\end{array}$ & $\begin{array}{c}\text { Conventional } \\
\text { Sialogram }\end{array}$ & $\begin{array}{c}\text { MR } \\
\text { Sialogram }\end{array}$ & $\begin{array}{c}\text { Conventional } \\
\text { Sialogram }\end{array}$ & $\begin{array}{c}\text { MR } \\
\text { Sialogram }\end{array}$ & $\begin{array}{c}\text { Conventional } \\
\text { Sialogram }\end{array}$ \\
\hline Sensitivity (\%) & 100 & 100 & 78 & 94 & 73 & 92 \\
\hline Specificity (\%) & 100 & 100 & 96 & 100 & 96 & 95 \\
\hline PPV (\%) & 100 & 100 & 91 & 98 & 91 & 94 \\
\hline NPV (\%) & 100 & 100 & 95 & 92 & 90 & 97 \\
\hline \multicolumn{7}{|c|}{ Table 2: Statistical Analysis } \\
\hline
\end{tabular}

Sensitivity of MR Sialography and conventional sialography for diagnosing chronic sialadenitis was $78 \%$ and $94 \%$, specificity being $96 \%$ and $100 \%$ respectively. False negatives in MRI were due to lower spatial resolution of the MRI. The changes in the secondary and tertiary branches were depicted in the Conventional sialography, which were not seen on MR Sialography. Positive and negative predictive values for Conventional sialography were 98\% and $92 \%$ respectively, and $91 \%$ and $95 \%$ for MR Sialography.

The patients with acute sialadenitis underwent MRI with MR Sialography during the acute phase and
Conventional sialography was done after a course of antibiotics.

MR and Conventional sialography showed normal ductal system in all examined. The sensitivity and specificity for both modalities were $100 \%$. However, MRI was superior to conventional sialography, as it could be done in acute phase. Imaging in the acute phase identified a case of intraparotid lymphadenitis, and hence Conventional sialography was deferred for that patient.

Sensitivity of MR Sialography and conventional sialography for diagnosing sialolithiasis was $73 \%$ and $92 \%$, specificity being $96 \%$ and $95 \%$ respectively. Positive and 
negative predictive values for Conventional sialography were $94 \%$ and $97 \%$ respectively, and $91 \%$ and $90 \%$ for MR Sialography.

MR Sialography showed false-negative results in two glands, which were due to small non-obstructing sialoliths. Sialectasis was identified in two patients due to chronic sialadenitis due to obstructing calculus.

\section{CONCLUSION}

From our study, we conclude that MR Sialography is a promising non-invasive technique for diagnosing the ductal abnormalities in major salivary glands. The advantages of MR Sialogram include no radiation hazard and non-invasive nature. Both the salivary glands can be easily imaged without change of the patient position. Images can be obtained with use of standard protocols and do not require special procedures (Cannulation).

MRI can be done in acute sialadenitis, where conventional sialography is contraindicated. This adds to an additional benefit of differentiating the pathologies with similar presentation as in intraparotid lymphadenitis. Ductal structures can also be visualized on either side of the obstruction, and even in cases of complete obstruction of the ductal system. MR Sialography has an excellent sensitivity for visualization of oedema in the salivary parenchyma, which is more difficult to diagnose with CT.

MR Sialography has the following limitations. The first being, low spatial resolution because of which secondary and tertiary branches could not be clearly visualised, and difficult to distinguish between complete and partial obstructions of the ductal system.

In conclusion, our results show that MR Sialography with a heavily $\mathrm{T} 2$-weighted sequence is a promising diagnostic tool and carries the potential to replace invasive imaging methods like X-ray sialography in patients suspected of having sialadenitis and/or sialolithiasis. However, conventional and digital subtraction sialography continue to be the standard technique for imaging the duct system.

\section{REFERENCES}

1. Kalinowski M, Heverhagen JT, Rehberg E, et al. Comparative study of MR sialography and digital subtraction sialography for benign salivary gland disorders. AJNR Am J Neuroradiol 2002;23(9):1485-92.

2. Koontz NA, Kralik SF, Fritsch MH, et al. MR sialography: a pictorial review. Neurographics 2014;4(3):142-57.

3. Uddin SM. Does MR sialography have a greater diagnostic accuracy than conventional x-ray and digital subtraction sialography in detecting salivary glands disease? A literature review. NJR 2011;1(1):70-7.

4. Yousem DM, Kraut MA, Chalian AA. Major salivary gland imaging. Radiology 2000;216(1):19-29.

5. Gadodia A, Seith A, Sharma R, et al. Magnetic resonance sialography using CISS and HASTE sequences in inflammatory salivary gland diseases: comparison with digital sialography. ACTA radiologica 2010;51(2):156-63.

6. Rastogi R, Bhargava S, Mallarajapatna GJ, et al. Pictorial essay: salivary gland imaging. Indian Journal of Radiology and Imaging 2012;22(4):325-33.

7. Bialek EJ, Jakubowski W, Zajkowski P, et al. US of the major salivary glands: anatomy and spatial relationships, pathologic conditions, and pitfalls. Radio Graphics 2006;26(3):745-63.

8. Becker M, Marchal F, Becker CD, et al. Sialolithiasis and salivary ductal stenosis: diagnostic accuracy of $\mathrm{mr}$ sialography with a three-dimensional extended-phase conjugate-symmetry rapid spin-echo sequence. Radiology 2000;217(2):347-58.

9. Jager L, Menauer F, Holzknecht N, et al. Sialolithiasis: MR sialography of the submandibular duct-an alternative to conventional sialography and US. Radiology 2000;216(3):665-71.

10. Reddy SS, Rakesh N, Namita Raghav, et al. Sialography: report of 3 cases. Indian J Dent Res 2009;20(4):499-502. 